\title{
LA TRADICIÓN DE LA GUERRA JUSTA Y EL CRIMEN DE AGRESIÓN*
}

\author{
Juan Francisco Lobo Fernández ${ }^{* *}$ \\ Universidad de Chile, Chile \\ juanfranciscolobo@gmail.com
}

\begin{abstract}
RESUMEN: La definición del crimen de agresión para la Corte Penal Internacional, acordada en la Conferencia para la Revisión del Estatuto de Roma en Kampala, 2010, es en realidad heredera de una tradición de data mucho más larga que el ius contra bellum, la tradición de la Guerra Justa. A través de un análisis del antiguo paradigma de guerra, así como de su mutación en el paradigma actual de la cacería, se busca establecer la relación de la guerra con la política y con la posibilidad de normarla mediante el discurso de la Guerra Justa.
\end{abstract}

Palabras clave: Guerra Justa, crimen de agresión, guerra, política.

\section{THE TRADITION OF FAIR WAR AND THE CRIME OF AGGRESSION}

\begin{abstract}
The definition of crime of aggression for the International Penal Court, agreed in the Conference for the Revision of the Statute of Roma in Kampala, 2010, is in fact, the heir of a tradition that dates back further beyond than the ius contra bellum, the tradition of the Fair War. Through an analysis of the old paradigm of war, just like from the mutation in the current paradigm of the hunting, it is sought an establishment relation between the war with the politics and with the possibility to dominate them by the discourse of the Fair War.
\end{abstract}

Keywords: Fair War, crime of aggression, war, politics.

Trabajo recibido el 30 de agosto y aprobado el 8 de octubre de 2011.

** Egresado de la Facultad de Derecho de la Universidad de Chile. Ayudante Ad-Honorem de las cátedras de Derecho Internacional de los Derechos Humanos y Teoría General del Derecho. Quisiera agradecer a Javier Gallego y Joaquín Trujillo por sus invaluables aportes bibliográficos, así como a José Zalaquett por sus oportunos comentarios y por haberme introducido en el estudio de la tradición de la Guerra Justa. 


\author{
“;Oh Perses! Grábate tú esto en el \\ corazón; escucha ahora la voz de \\ la justicia y olvidate por completo \\ de la violencia. Pues esta ley impuso \\ a los hombres el Cronión: a los peces, \\ fieras y aves voladoras, comerse los \\ unos a los otros, ya que no existe \\ justicia entre ellos; a los hombres, \\ en cambio, les dio la justicia, que \\ es mucho mejor". \\ HESIOODO, Los trabajos y los días.
}

\section{INTRODUCCIÓN}

Desde las Conferencias de Paz de La Haya de 1899, pasando por el pacto Briand-Kellogg de 1928, hasta la Carta de las Naciones Unidas y los juicios de Nüremberg y Tokyo de 1945, se ha intentado erradicar la guerra de agresión como forma de solución de controversias en el plano internacional.

En la resolución No 3314, de 1974, la Asamblea General de las Naciones Unidas la definió como "el uso de la fuerza armada de un Estado contra la soberanía, la integridad territorial o la independencia política de otro Estado, o en cualquier otra forma incompatible con la Carta de las Naciones Unidas" (art. 1). El Estatuto de Roma, que creó la Corte Penal Internacional en 1998, incluyó entre los delitos de su competencia al crimen de agresión (art. 5.1), para ser definido en el futuro (arts. 121 y 123).

En efecto, el 11 de junio de 2010, tras la primera Conferencia de Revisión del Estatuto de Roma, realizada en Kampala (Uganda), los Estados Miembros definieron el crimen de agresión en un nuevo artículo 8 bis $^{1}$, como el epítome del largo camino de un ius contra bellum iniciado con las Conferencias de Paz de La Haya, aunque sólo se trató de la reiteración de la definición contenida en la resolución 3314 de la Asamblea General de la ONU².

\footnotetext{
"Crimen de agresión:

1. A los efectos del presente Estatuto, una persona comete un "crimen de agresión" cuando, estando en condiciones de controlar o dirigir efectivamente la acción política o militar de un Estado, dicha persona planifica, prepara, inicia o realiza un acto de agresión que por sus características, gravedad y escala constituya una violación manifiesta de la Carta de las Naciones Unidas.

2. A los efectos del párrafo 1, por "acto de agresión" se entenderá el uso de la fuerza armada por un Estado contra la soberanía, la integridad territorial o la independencia política de otro Estado, o en cualquier otra forma incompatible con la Carta de las Naciones Unidas (...)".

2 Más aún, la lista de conductas constitutivas de agresión que incluye el nuevo artículo 8 bis. 2 es idéntica a la del artículo 3 de la Resolución 3314, como lo seńala expresamente el mismo art. 8bis.2.

En cuanto a los bienes jurídicos protegidos por el derecho penal internacional (i.e. la paz, la seguridad y el bienestar de la humanidad) ellos coinciden con los objetivos de las Naciones Unidas, plasmados en el art. 1 de la Carta. Véase WerLe, Gerhard. Tratado de Derecho Penal Internacional. Valencia, España: Tirant Lo Blanch, 2005, p. 79.
} 
Pues bien, no es el objeto de la presente reflexión indagar sobre los inconvenientes que pudieran surgir de la definición de un tipo penal sustraída de una regulación de la conducta estatal, ni acerca de cualquier otra problemática en general que repercuta en la doctrina penal ${ }^{3}$. Ello puede parecer extraño si se considera que se trata de una reflexión en torno al "crimen" de agresión.

Sin embargo, se advierte desde ya que el crimen de agresión no es tan sólo el epítome del proceso jurídico-pacifista que comenzó a fines del siglo XIX, sino también es heredero de una tradición mucho más antigua que hunde sus raíces hasta el mismo Platón ${ }^{4}$.

Se trata de la tradición de la Guerra Justa, una conversación milenaria acerca de la legitimidad de librar una guerra ${ }^{5}$, que adopta la forma de una "convención de la guerra", o normas, costumbres, códigos, preceptos legales y principios filosóficos que modelan nuestros juicios acerca de la guerra ${ }^{6}$. Cuando en la definición de la agresión, o del crimen de agresión (para estos efectos, idénticos desde 1974 a 2010), se dice que un acto de agresión es el uso de la fuerza de cualquier forma incompatible con la Carta de las Naciones Unidas, lo que se quiere decir es que la agresión se encuentra en las antípodas de lo que se entiende por Guerra Justa. Ello por cuanto los requisitos que dentro de esta tradición se han esgrimido para calificar una guerra como justa (i.e. justa causa, autoridad legítima, recta intención, necesidad, proporcionalidad), como se verá, se encuentran desperdigados todo a lo largo de la Carta de la ONU. En otras palabras, cuando la Carta de la ONU proscribió la guerra, dejando todavía un lugar para actos de agresión lícitos, lo que recogió entre sus disposiciones fue un concepto de Guerra Justa de larga prosapia, que está reñido con una guerra de agresión.

Ahora bien, antes de emprender el análisis del crimen de agresión como "guerra injusta", es necesario esclarecer qué es aquello que la tradición de la Guerra Justa califica tanto adjetival como adverbialmente (en la forma de ius ad bellum y ius in bello). Esto es, en qué consiste el concepto sustantivo a que se refiere la tradición: la guerra. Pero para poder entender la guerra y su regulación, es decir, su relación con el derecho y la moral, es imprescindible comprender primero su relación con el fenómeno de lo político. Para conducir esta empresa reconstructiva de la relación entre guerra, política y derecho, se recurrirá a tres paradigmas (i.e. modelos o ejem-

3 Para distintos análisis a través de la óptica penal, véase Heinsch, Robert. The Crime of Aggression after Kampala: Success or burden for the future? En: Goettingen Journal of International Law, 2(2): 713-743, 2010; InstituTO DE DEMOCRACIA Y Derechos Humanos (IDEHPUCP), PUC del Perú. El crimen de agresión después de Kampala: Soberania de los Estados y luch a contra la impunidad. Lima, Perú: IDEHPUCP, 2011; DE Nicola, Christopher. A shield for the "Knights of Humanity": The ICC should adopt a humanitarian necessity defense to the crime of aggression. En: University of Pennsylvania International Law Review, 30(2): 641-689, 2008; O'Connor, Laurie. Humanitarian Intervention and the Crime of Aggression: The precarious position of the "Knights of Humanity". Tesis (Bachiller en Derecho), Dunedin, Nueva Zelanda: Universidad de Otago, 2010.

4 Platón argumentaba en Las Leyes que sólo se debía iniciar una guerra en pos de la paz, y en La República que existen normas que rigen las hostilidades, aunque sólo entre griegos. Véase Bellamy, Alex. Guerras Justas. De Cicerón a Irak. Buenos Aires, Argentina: FCE, 2009, p. 44.

5 Ibid, p. 22.

6 Walzer, Michael. Guerras Justas e Injustas. Buenos Aires, Argentina: Goyanarte Editor S.A., 1980, p. 70. 
plos en términos de Kuhn) sustraídos de lo que Hannah Arendt considera el mito fundante de occidente, La Ilíada, y su corolario narrativo, La Eneida. En primer lugar, se describirá la era de Aquiles. Luego, el advenimiento de Ulises. Por último, el regreso de Eneas.

\title{
2. LA ERA DE AQUILES
}

\author{
“(...) las tropas integradas por buenos \\ ciudadanos resisten hasta la muerte (...). \\ $Y$ ello es asi, porque para estos la huida \\ es deshonrosa y la muerte es preferible \\ a este modo de salvación. \\ Los soldados profesionales, en cambio, \\ afrontan decididamente el peligro al \\ principio, confiados en su superioridad, \\ pero, cuando se dan cuenta de la realidad, \\ huyen porque temen la muerte más que \\ la deshonra. El valiente no es asi". \\ ARISTÓTELES, Ética a Nicómaco.
}

En su reciente obra Rage and time, Peter Sloterdijk afirma que la "primera palabra" de Europa es aquella que encabeza el canto primero del mito fundante de occidente, La Ilíada. Se trata de la ira (o cólera ${ }^{8}$. Para Sloterdijk, La Ilíada es el poema de la ira (menis), así como La Odisea es el poema de la astucia ${ }^{9}$ (metis).

Sobre La Ilíada como el poema de la fuerza ya se había pronunciado antes Simone Weil, en plena Segunda Guerra Mundial ${ }^{10}$. Sin embargo, más allá de una lectura justificadamente pesimista de la violencia en el mito fundante, o de la violencia en general (a la manera del pesimismo de Walter Benjamin ${ }^{11}$ ), lo que busca Sloterdijk es desentrañar el potencial constructivo que entrańa la ira como motor de la historia, pues la historia no es sino la ira aplicada ${ }^{12}$.

\footnotetext{
Arendt, Hannah. ¿Qué es politica? Barcelona, España: Paidós, 1997, pp. 116-117.

Sloterdijк, Peter. Rage and time. A psychopolitical investigation. New York, Estados Unidos: Columbia University Press, 2010, p. 1. 
Sloterdijk sostiene que en el milenio que sucedió a Homero, Aquiles fue un "tópico" (lugar común) reiterado en el mundo mediterráneo ${ }^{13}$, es decir, un verdadero paradigma. Tal aseveración coincide con la evaluación de Alisdair MacIntyre acerca de la concepción que de sí misma tenía la sociedad clásica en tanto heredera de la sociedad heroica ${ }^{14}$.

\section{I. De BeLlum}

Pues bien, si Aquiles era un paradigma clásico es necesario dilucidar su quehacer fundamental para entenderlo como modelo o ejemplo. Es necesario definir la guerra.

Hugo Grocio, uno de los exponentes de la mentada tradición de la Guerra Justa, define la guerra como un estado, no una acción, en particular "el estado de los que combaten por la fuerza" ${ }^{15}$. En esta definición coincide con su contemporáneo Thomas Hobbes, para quien la guerra es también un estado ${ }^{16}$. Grocio rastrea la etimología de la voz latina para guerra, bellum, hasta la expresión antigua duellum, hoy duelo, es decir, el enfrentamiento entre dos ${ }^{17}$.

A igual conclusión llegaría más tarde el general prusiano Karl Von Clausewitz, quien definió a la guerra como "un acto de fuerza para imponer nuestra voluntad al adversario"18, no siendo más que "un duelo a escala ampliada" 19 .

Ahora bien, parece adecuado recurrir a una mirada más objetiva sobre el fenómeno de la guerra, para obtener una conceptualización del mismo que no provenga desde la trinchera (figurativa) del jurista o diseńador del Estado, ni de la trinchera (real) del militar. Hace falta una aproximación antropológica, como aquella llevada a cabo por el francés Pierre Clastres.

Clastres intenta indagar en el estado de naturaleza hobbesiano, no sólo como un tópico teórico, sino como lo que según el propio Hobbes aún sucedía, en su tiempo, entre los salvajes de América ${ }^{20}$. De este modo (y a excepción de los esquimales), la guerra adquiere en las socie-

Ibíd, p. 5.

1 MacIntyre, Alasdair. After Virtue -3a edición.- Indiana, Estados Unidos: University of Notre Dame Press, 2007, pp. 121, 131.

15 Grocio, Hugo. Del derecho de la Guerra y de la paz. Madrid, España: Editorial Reus, 1925, Tomo I, p. 45.

16 Новвеs, Thomas. Leviatán, o de la materia, forma y poder de una república eclesiástica y civil. Buenos Aires, Argentina: Fondo de Cultura Económica, 1992, p. 102.

17 Grocio, Hugo, op. cit. (n.15) p. 45.

18 Von Clausewitz, Karl. De la Guerra. Buenos Aires, Argentina: Distal, 2006, p. 19.

19 Ibid, p. 19.

20 Hobbes, Thomas, op. cit. (n.16), p. 104. 
dades primitivas, afirma Clastres, un carácter de universalidad ${ }^{21}$, sentencia en la que reverberan las palabras de Platón en Las Leyes, "sólo los muertos han visto el fin de la guerra", y las de De Maistre, "la efusión de sangre humana no es nunca suspendida en el universo"22.

Clastres descarta las explicaciones tradicionales acerca del fenómeno de la guerra. Es así como refuta el "discurso naturalista" de Leroi-Gourhan, que ve en la guerra una propiedad zoológica no diferente de la cacería, por cuanto en la guerra no se busca la alimentación, como es el caso de la caza ${ }^{23}$. Luego, descarta el "discurso economicista", que postula que la escasez de bienes y la infinidad de necesidades es la causa de la guerra, ya que se ha demostrado que la economía primitiva es una de la abundancia, y no de la escasez ${ }^{24}$. Por último, rechaza la "noción de intercambio" de Lévi-Strauss, según la cual la guerra es el dorso negativo de la transacción comercial, por cuanto la sociedad primitiva es esencialmente autárquica en lo económico ${ }^{25}$.

Clastres llega a la conclusión de que la guerra es una "estructura de la sociedad primitiva”, ya que la unidad-totalidad en la que consiste esa sociedad tiende hacia el exterior a ladispersión, como una fuerza centrífuga, para permanecer en el interior en la indiferenciación de clases $^{26}$, ya que el enemigo externo cohesiona en el interior (lo que Chnatal Mouffe llama el "exterior constitutivo"27), y "si los enemigos no existieran, habría que inventarlos"28.

Lo más importante que se puede extraer de la teoría de Clastres es que la guerra es esencialmente diferente de la cacería, pero no sólo porque la postrera busca el sustento y la primera persigue otras finalidades (políticas), sino más aún porque la guerra es un hecho institucional.

\subsection{LA GUERRA COMO HECHO INSTITUCIONAL}

Francois Bugnion, miembro del Comité Internacional de la Cruz Roja, ha señalado que la guerra es una forma institucionalizada de violencia ${ }^{29}$.

Un hecho institucional es, según John Searle, el resultado de un proceso que se inicia con un hecho bruto (i.e., hechos tal y como nos los presenta el mundo). A partir del hecho bruto un conjunto de personas participan de una convención, en la cual mediante una regla cons-

21 Clastres, Pierre. Arqueología de la violencia: la guerra en las sociedades primitivas -2a edición-. Buenos Aires, Argentina: Fondo de Cultura Económica, 2009, p. 14.

22 De Maistre, Joseph. Consideraciones sobre Francia. Madrid, España: Tecnos, 1990, p. 31.

23 Clastres, Pierre, op. cit. (n.21), p. 22.

24 Ibid, p. 31.

25 Ibid, p. 36

26 Ibid, pp. 40-55.

27 Mouffe, Chantal. El retorno de lo político. Barcelona, España: Paidós, 1999, p. 15.

28 Clastres, Pierre, op. cit. (n.21), p. 73.

29 Bugnion, Francois. "Guerra justa, guerra de agresión y derecho internacional humanitario", en: Revista Internacional de la Cruz Roja, No 847: 523-546, 2002, p. 2. 
titutiva confieren un nuevo status a ese hecho bruto, que ahora adquiere una nueva función, distinta a la que le es natural. Con la adquisición de esa nueva función se ha creado un hecho institucional, como el dinero o el derecho ${ }^{30}$.

Searle llama la atención sobre dos aspectos importantes para lo que aquí interesa acerca de los hechos institucionales. En primer lugar, el hecho institucional, en tanto convencional, posee una función comunicativa, por cuanto se expresa en símbolos lingüísticos, sean o no palabras (por ejemplo, un montón de piedras a modo de frontera), que se caracterizan por "simbolizar" (hacer referencia a algo fuera de ellos), ser convencionales y públicos ${ }^{31}$.

En segundo lugar, el hecho institucional no sólo implica un "paso simbolizador" a partir del hecho bruto, sino además un paso normativo, por cuanto el status asignado tiene carácter deóntico (relativo al "deber ser"), expresado en la regla constitutiva enunciada del modo "X cuenta (obligatoriamente) como Y en Z"32.

Pues bien, uno de los teóricos contemporáneos más importantes de la tradición de la Guerra Justa, Michael Walzer, en su texto canónico sobre la materia Guerras justas e injustas, comienza refutando el realismo y su consigna inter arma silent leges, postulando lo que él llama "la realidad moral de la guerra": "Reiterados a través del tiempo, nuestros argumentos y juicios dan forma a lo que quiero llamar la realidad moral de la guerra; es decir, todas esas experiencias de las cuales es descriptivo el lenguaje moral o dentro de las cuales es empleado necesariamente. (...) Es con la asignación de esos significados como hacemos de la guerra lo que es"33. Sólo sobre la base de esa realidad moral podemos hablar de una guerra en términos tan disímiles como agresión, defensa propia, crueldad o masacre ${ }^{34}$. Continúa Walzer: "(...) lo decisivo no es lo que la gente hace, sus movimientos físicos, sino las instituciones, prácticas y convenciones que realizan. De ahí que las condiciones sociales e históricas que 'modifican' la guerra no deban ser consideradas como accidentales o externas a la guerra misma, porque la guerra es una creación social. (...) Lo que es guerra y lo que no es guerra es en realidad algo que la gente decide”35.

A la luz de lo anterior, se puede decir que la guerra es un hecho institucional con implicancias tanto deónticas como simbolizadoras. Las primeras serán analizadas más adelante al referirnos a la Guerra Justa. Las segundas ayudarán a entender en qué consiste el paradigma antiguo de guerra, representado por Aquiles.

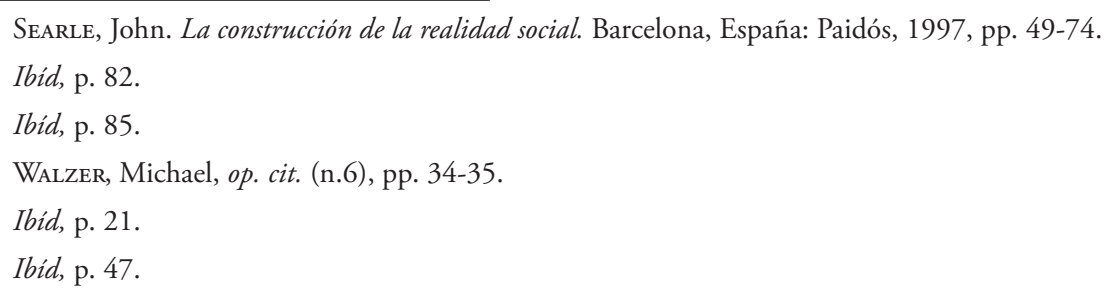




\subsection{Violencia comunicativa. ¿Contradictio in adjecto?}

Hannah Arendt ha definido el poder como la capacidad humana para actuar colectivamente, "potencialidad de la vida en común", que existe donde acción (capacidad de iniciar algo espontáneamente) y discurso no se han escindido ${ }^{36}$. La violencia, en cambio, es lo esencialmente instrumental ${ }^{37}$. En esto sigue a Simone Weil, para quien la fuerza ${ }^{38}$ instrumentaliza no sólo al que es víctima de ella, sino también a su sujeto activo, y ambas coinciden en que la violencia es muda $^{39}$ (no comunicativa).

Sin embargo, Arendt reconoce que violencia y poder pueden estar combinados, por ejemplo en la revolución ${ }^{40}$, y más aún, en todo gobierno la violencia siempre depende de un poder que la sostenga ${ }^{41}$. De ahí que se pueda hablar de un "poder violento" o de un "poder con violencia” ${ }^{\prime 2}$.

Por su parte, Sloterdijk concibe a la ira como un fenómeno comunicativo, en un doble sentido. En su forma heroica-mítica, la ira es el medio de comunicación de los dioses con los hombres, a través del centro impulsivo y sensor de la voluntad de aquellos que es el "alma" thy$m_{o s}{ }^{43}$. Mediante este sensor los hombres comprenden que el deseo de los dioses es hacer de ellos los seres tozudos del $\operatorname{cosmos}^{44}$, los seres que ante la adversidad no se amilanan sino que le hacen frente y la conquistan, cuantas veces se requiera. En segundo lugar, la thymos domesticada, en la forma de valor masculino o andreia, es admitida dentro de la polis clásica como "ira justa", o la ira que se suscita por falta de reconocimiento, tanto ante uno mismo (por no cumplir las propias expectativas), cuanto frente a los demás cuando no nos reconocen como iguales (siguiendo la imagen hegeliana $\left.{ }^{45}\right)$. Esta ira es apelativa, pues expresa reproche.

Existe aún otro sentido en que puede existir una violencia o ira comunicativa ${ }^{46}$, y arranca de lo que intuitivamente podría considerarse tierra estéril para esta conceptualización. Se trata de la ética discursiva. Como es sabido, para Jürgen Habermas el discurso es una forma

\footnotetext{
36 Arendt, Hannah. The human condition. Chicago, Estados Unidos: The University of Chicago Press, 1958 , p. 200.

37 Arendt, Hannah. Sobre la violencia. Madrid, España: Alianza Editorial, 2006, p. 63.

38 Para Arendt la fuerza es diferente de la violencia, pues se refiere sólo a la liberación de energía. Violencia, p. 61. Sin embargo, tanto Arendt al referirse a la violencia, como Weil al hablar de la fuerza, llegan a iguales conclusiones.

39 Arendt, Hannah, op. cit. (n.36), p. 26. Weil, Simone, op. cit. (n.10), p. 22.

40 Arendt, Hannah, op. cit. (n.37), p. 65.

41 Ibid, p. 69.

42 Parece más lógica esta última expresión, ya que al ser opuestos poder y violencia, como lo comunicativo lo es con lo instrumental, decir "poder violento" equivale a decir "blanco negro". Lo que sí tiene sentido decir es "blanco con negro", es decir, "poder con violencia".

43 Sloterdijk, Peter, op. cit. (n.8), p. 11.

44 Hoy thymos se traduciría más precisamente como "tenacidad".

45 Ibid, p. 24

46 José Zalaquett ha acometido una empresa similar al aplicar por analogía los requisitos de la Guerra Justa a un acto comunicativo por definición, la desobediencia civil en Rawls. Véase ZaLaquetT, José. La desobediencia civil en John Rawls y la ética de
} 
de comunicación caracterizada por la argumentación, en que se han tornado problemáticas las pretensiones de validez usualmente inconcusas en la acción comunicativa (orientada al entendimiento y no al éxito ${ }^{47}$ ), perfilándose tal forma de comunicación como la interrupción, con cargo a su restablecimiento, de un fragmento temático de la acción comunicativa y de su supuesto, el mundo de la vida ${ }^{48}$.

El resultado de una tal forma de comunicación será una "verdad consensuada", pero sólo en la medida en que se haya observado un cierto procedimiento que garantice la máxima asertividad de esa nueva verdad ${ }^{49}$. Tal procedimiento adopta la forma de una "situación ideal de habla", en que cada quien tiene iguales oportunidades de aportar contenidos sin exclusiones, y en que no hay más coacción que aquella del mejor argumento ${ }^{50}$. Con base a la aceptabilidad racional de las normas producidas en el discurso se podrá predicar de ellas que son legítimas (principio discursivo "D"51).

Pues bien, quisiera tomar en serio una analogía introducida por John Stuart Mill en su célebre ensayo On Liberty, acerca del discurso. Recurrir a Mill permite, a juicio de MacIntyre, disminuir la brecha que separa el mundo antiguo del individualismo moderno ${ }^{52}$. Por tanto, es un autor adecuado para intentar comprender desde el presente el paradigma de violencia comunicativa encarnado en la persona de Aquiles.

$\mathrm{Al}$ referirse a la libertad de pensamiento y discusión, Mill afirma que quienes discuten luchan como combatientes bajo diferentes estandartes ${ }^{53}$. Su imagen bélica para referirse al discurso puede ser tomada en serio en el sentido de dejar de ser una imagen. Si la tesis de este ensayo es correcta, el carácter fuertemente contraintuitivo de una propuesta de la "guerra como discurso" sólo probará la existencia del paradigma de guerra que se describe aquí, así como su desplazamiento por otro paradigma.

Pues bien, el carácter discursivo de la guerra antigua se vuelve manifiesto en la manera de librarla, esto es, abiertamente y frente a frente, con vestimenta y estandartes distintivos de cada

medidas de excepción y de medidas extremas, en: Derecho y Humanidades, № 12. Santiago, Chile: Facultad de Derecho, Universidad de Chile, 2006, pp. 121-132.

47 Siendo el entendimiento un acuerdo entre sujetos interactiva y lingüísticamente competentes. Véase Habermas, Jürgen. Teoría de la acción comunicativa, I. Madrid, España: Taurus, 1981, p. 124.

48 Habermas, Jürgen. Teoría de la acción comunicativa. Complementos y estudios previos. Madrid, España: Cátedra, 1984, p. 116.

49 Ibid, p. 140; Habermas, Jürgen. Verdad y justificación. Madrid, España: Trotta, 2002, p. 277.

50 Habermas, Jurgen, op. cit. (n.48), p. 153.

51 Habermas, Jürgen. Conciencia moral y acción comunicativa. Barcelona, España: Península, 1983, p. 86.

52 MacIntyre, Alasdair, op. cit. (n.14), p. 137.

53 "Truth, in the great practical concerns of life, is so much a question of the reconciling and combining of opposites that very few have minds sufficiently capacious and impartial to make the adjustment with an approach to correctness, and it has to be made by the rough process of a struggle between combatants fighting under hostile banners". Mill, John Stuart. On Liberty. New York, Estados Unidos: The Liberal Arts Press, 1956, p. 58. 
bando ${ }^{54}$, e incluso música, todos símbolos portadores de contenido. Su carácter confrontacional es mejor ilustrado en un pasaje de La Ilíada: “(...) pues eran paladines selectos los que aguardaban a los troyanos y al divino Héctor (...). Se apoyaban broquel en broquel, casco en casco, hombre en hombre. Los empenachados cascos se tocaban con los brillantes crestones al menear la cabeza: ¡tan apińados unos con otros formaban! Hacían entrelazarse las picas, que en las audaces manos vibraban, y no tenían otra idea que avanzar y ansiar la lucha”.

La formación de ataque en conjunto, que a juicio de William McNeill es una excelente fuente del sentido de comunidad mediante lo que él llama el "lazo muscular" 55 , es característica de los primeros ejércitos occidentales (griegos y romanos), y explica la superioridad militar de occidente todo a lo largo de la historia, de acuerdo a Víctor Davis. Para él, los réditos de una cultura como la helénica, caracterizada por la libertad personal, la disciplina, la camaradería igualitaria, la libertad de expresión y la preferencia por las batallas de choque ("batallas decisivas"), se traducen en hegemonía en el campo de batalla desde Maratón hasta Irak ${ }^{56}$.

Hasta aquí parece evidente la semejanza entre el concepto de poder en Arendt y el lazo muscular de McNeill, así como la similitud entre la situación ideal de habla y la guerra librada frente a frente con iguales oportunidades para atacar. Sin embargo, no se trata de identificar guerra y discurso. Si bien tienen semejanzas, lo cierto es que el resultado de un enfrentamiento no es igual al de un discurso. La verdad consensuada tiene su equivalente como out-put en la guerra, pero no es su igual; es la muerte.

Para Martin Heidegger al "ser ahî" o dasein, es decir, al ser humano ${ }^{57}$, es inherente o constitutivo un "aún no", "lo que falta" 58 , siendo la muerte la llegada a la totalidad (el cese de lo incompleto que es el dasein). Mientras que "finar" es el cese biológico del dasein, "morir" es un modo de ser del dasein, que consiste en que "es relativamente a la muerte" (se orienta hacia la muerte),

54 Si bien el uniforme profesional se remonta hasta los romanos, durante la Edad Media cayó en desuso y fue reemplazado por colores en la vestimenta e insignias heráldicas, hasta que con el abandono de la armadura en el s. XVI, se hizo necesario de nuevo el uniforme, que contribuyó también a la formación de la identidad nacional de los incipientes Estados post-westfalianos. Véase Pfanner, Toni. Military uniforms and the law of war. International Review of the Red Cross, 86(853): 93-124, marzo, 2004, pp. 96-98.

55 McNeill, William. Keeping together in time. Cambridge, Estados Unidos: Harvard University Press, 1995, p. 2.

56 Davis, Víctor. Matanza y cultura. Batallas decisivas en el auge de la civilización occidental. D.F., México: Fondo de Cultura Económica, 2006, p.20. Tal vez la superioridad militar de occidente se deba a los tempranos enfrentamientos entre los hombres de Cro-Magnon (homo sapiens) y los hombres de Neanderthal, que tuvieron lugar en Europa en el paleolítico superior, haciendo los neanderthalienses las veces de un "exterior constitutivo" primigenio que perfeccionó al hombre europeo en el arte de la guerra. Véase Hublin, Jean-Jacques y Tillier, Anne-Marie (comp.). Homo Sapiens. En busca de sus orígenes. D.F., México: Fondo de Cultura Económica, 1999, p. 178.

57 Llamado así porque es un ente que puede preguntarse por el enigma tras de todos los entes, es decir, por el ser, y porque su estructura es la de "ser en el mundo", donde el "mundo" es el fenómeno que permite captar el ser de los entes, mientras que "ahî" quiere decir espacialidad existenciaria, familiaridad, compuesta por lo "aquî" del yo, y lo "alli" de lo a la mano. El dasein es en esencia "cura" o cuidado, empeño, esfuerzo.

58 Heidegger, Martin. El ser y el tiempo. -2a ed.-, Buenos Aires, Argentina: Fondo de Cultura Económica, 2010, p. 265. 
pero por el acontecimiento de la muerte no finaliza, sino que es sólo otro modo de ser que tiene ${ }^{59}$. La muerte es una posibilidad del dasein, la más peculiar entre todas, pues es la posibilidad de su imposibilidad ${ }^{60}$. Cuando el dasein acepta su "precursar" (su ser relativamente a la muerte) adquiere una libertad relativa a la muerte, expresada en el desapego por la propia existencia ${ }^{61}$.

El dasein es un "deudor" en el sentido de que es el fundamento (la causa) de un "no ser", pues encierra en sí mismo su propia negación, la negación de su ser, la muerte ${ }^{62}$.

Heidegger se preocupa de diferenciar la "deuda" del dasein en el sentido de ser portador de su propia negación, con la "deuda" en sentido vulgar, es decir, un déficit respecto a otro, como quiera que la muerte es netamente personal ${ }^{63}$.

Sin embargo, el sentido jurídico de deuda todavía puede ser invocado para explicar el resultado de la guerra, la muerte. Ello por cuanto el propio Heidegger acepta que la muerte es una certidumbre empírica, pero indeterminada, es decir, puede sobrevenir en cualquier momento ${ }^{64}$. Quienes combaten en una guerra son por cierto, como todo ser humano, deudores de la muerte en el sentido esbozado por Heidegger (portadores de su propia negación). Pero al ser la muerte una igualmente inminente condición de esos combatientes, en tanto todos son dasein, se torna en un elemento equiparador, pues la guerra "a todos doblega por igual" (La Ilíada).

Si ya no se trata sólo de una "deuda" personal, sino una que iguala a todos sus destinatarios pasivos, y que al mismo tiempo puede ser liquidada en cualquier momento, entonces nos encontramos cerca de la figura jurídica de la "solidaridad pasiva". Tan sólo falta que el acreedor pueda dirigirse contra cualquiera de los codeudores solidarios por el total de la deuda. Tal vez el primer hombre muerto en toda la historia fue quien saldó la deuda con la muerte, y su descendencia se encargó de repetir en contra de los demás codeudores solidarios su parte (su vida) en la contribución a la deuda. Tal vez así nació la guerra, como solidaridad ante la muerte.

De este modo podemos al fin presentar a Aquiles, de pies ligeros, como el paradigma de la guerra antigua. Su ira buscó comunicar la voluntad divina así como la demanda por el reconocimiento. Su violencia es comunicativa pues es apelativa y produce un resultado en común: la muerte. Su sangre, igual en color a la de todos los demás seres humanos, es el símbolo de la deuda común que tenemos con la muerte ${ }^{65}$, que nos iguala y que se presenta en forma líquida, dotando de sentido a la anfibología del verbo "liquidar". Esa deuda líquida, exigible en todo

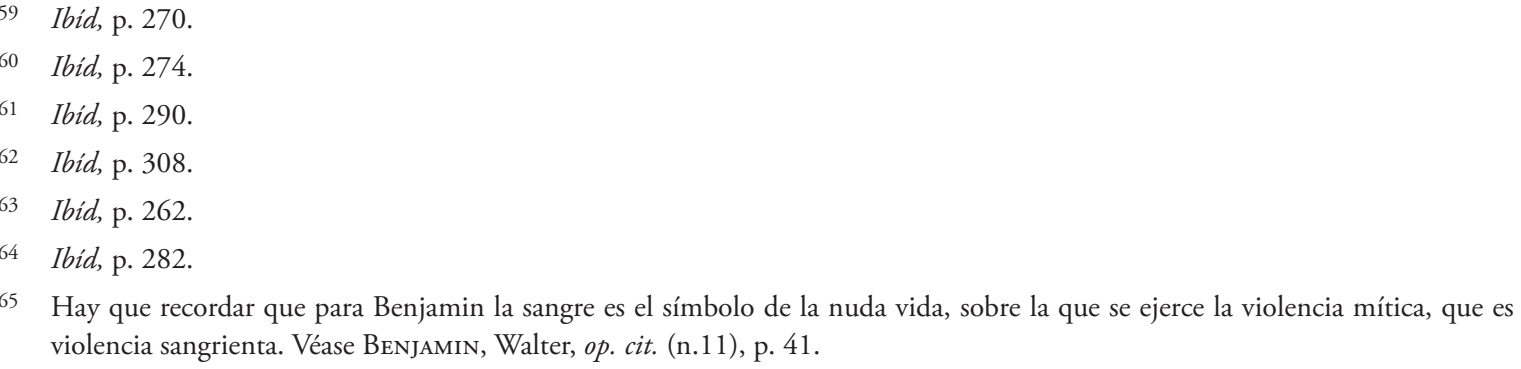

65 Hay que recordar que para Benjamin la sangre es el símbolo de la nuda vida, sobre la que se ejerce la violencia mítica, que es violencia sangrienta. Véase Benjamin, Walter, op. cit. (n.11), p. 41. 
momento a cualquiera de nosotros, también adopta otra forma líquida universal: las lágrimas. Cuando Príamo se escabulle en la tienda de Aquiles para recuperar el cuerpo vejado de su hijo asesinado, existe un momento de reconocimiento entre ambos, que Weil cree ver en su admiración mutua ${ }^{66}$, pero que en realidad toma la forma del llanto en conjunto, recordando ambos a sus seres queridos que ya han contribuido a la deuda. En realidad las lágrimas no son un pago de la deuda, sino un anticipo de su inminencia, lo que Heidegger denominó la "angustia frente a la muerte" 67 .

\subsection{GUERRA Y POLÍtICA: EL CONTINUUM ANTROPOLÓGICO FUNDAMENTAL}

Tras la asimilación de los conceptos de guerra y discurso se podría hacer lo propio con los conceptos de guerra y política deliberativa, es decir, aquel modelo de política propuesto por la ética discursiva de Jürgen Habermas ${ }^{68}$. Sin embargo, la relación entre guerra y política es más compleja que la de una simple semejanza.

De ese modo lo entendió el ya citado Karl Von Clausewitz, cuando definió a la guerra como "la continuación de la política por otros medios". Esto significa que la guerra es un medio de la política y a ella está subordinada ${ }^{69}$, tesis que apoyó durante el siglo XX Raymond Aron $^{70}$.

Por el contrario, tanto para Carl Schmitt como para Michel Foucault, así como para William McNeill, "la política es la continuación de la guerra por otros medios".

En efecto, para Schmitt la política, al estar constituida por la dicotomía fundamental amigo-enemigo, presupone la "posibilidad real de la eliminación física"71. "La guerra no es pues un fin o una meta, o tan sólo el contenido de la política, sino que es su presupuesto siempre presente como posibilidad real (...)"72.

Por su parte, Michel Foucault se refiere a la guerra como "relación social permanente"73, la hipóstasis fundamental que sirve de motor a todas las instituciones y a todo el orden. Si parece no estar ahí, es sólo porque con el Estado nacional se la relegó, aparentemente, a las

\footnotetext{
66 WeIL, Simone, op. cit. (n.10), p. 24.

67 Heidegger, Martin, op. cit. (n.58), p. 289.

68 Esto es, un modelo que supere el subjetivismo del liberalismo y del republicanismo, hacia un intersubjetivismo, en que se puedan desenvolver discursos éticos, morales y pragmáticos con la garantía de un procedimiento racional. Véase Habermas, Jürgen. Facticidad y validez. Sobre el derecho y el Estado democrático de derecho en términos de teoría del discurso. $4^{a}$ ed., Madrid, Trotta, 2005, pp. 363 y ss.

69 Von Clausewitz, Karl, op. cit. (n.18), p. 30.

70 Durán, Roberto. Las relaciones internacionales en la concepción de Raymond Aron. <En línea> [Citado en 27 Junio 2011] Disponible en World Wide Web: <http://www.uc.cl/icp/revista/pdf/rev61/ar2.pdf>, p. 13.

71 Sснмiтt, Carl. El concepto de lo "político". En: Aguilar, Orestes. Carl Schmitt: Teólogo de la política. México, Fondo de Cultura Económica, 2001, p. 183.

72 Ibid., p. 184.

73 Foucault, Michel. Defender la sociedad. -2a ed.-. D.F., México: Fondo de Cultura Económica, 2006, p. 54.
} 
fronteras. Pero en realidad nunca se fue ${ }^{74}$. Esa relación social permanente se manifiesta en la forma de lucha (real, no figurada) de "razas" (culturas, como los francos y los galo-romanos, o los normandos y los sajones), luego de clases, y luego de razas como tales en el siglo $\mathrm{XX}^{75}$. Foucault despoja a Hobbes del título de primer teórico de la continuidad entre la guerra (de todos contra todos) y la política, por cuanto Hobbes admite una forma de constitución del soberano sin lucha: la autoridad paterna y materna ${ }^{76}$. Foucault intenta rastrear el apotegma de Clausewitz hasta un aristócrata francés del siglo XVII, llamado Boulanvilliers, quien fue el primero en comprender que la política es la continuación de la guerra por otros medios ${ }^{77}$.

A igual conclusión arriba McNeill, cuando afirma que la formación en conjunto de la falange griega redundó en una ciudadanía activa y cohesionada ${ }^{78}$.

Lo anterior entronca con el concepto de Hannah Arendt de lo político, no como una condición natural "del hombre" aislado (zoon politikon en Aristóteles), sino como algo que sucede "entre los hombres" (como la capacidad de habla del zoon logon ekhon del mismo Aristóteles), pues necesita del sustrato imprescindible del pluralismo ${ }^{79}$.

¿De dónde viene ese pluralismo? Dado que la guerra es entendida por Grocio y Clausewitz como un duelo a escala ampliada, el factum de la pluralidad de partes es condición, antes que de la política, de la misma guerra, de la cual aquélla es sólo la continuación. Tal es el continuum antropológico fundamental: la guerra y la política son lo que sucede entre hombres, entre guerreros-ciudadanos, pues "los soldados son los ciudadanos de la tierra gris de la guerra" (Sasoon). Es por eso que la lucha (agôn) es una parte fundamental del genio de los griegos, desde la guerra hasta sus competiciones y debates ${ }^{80}$.

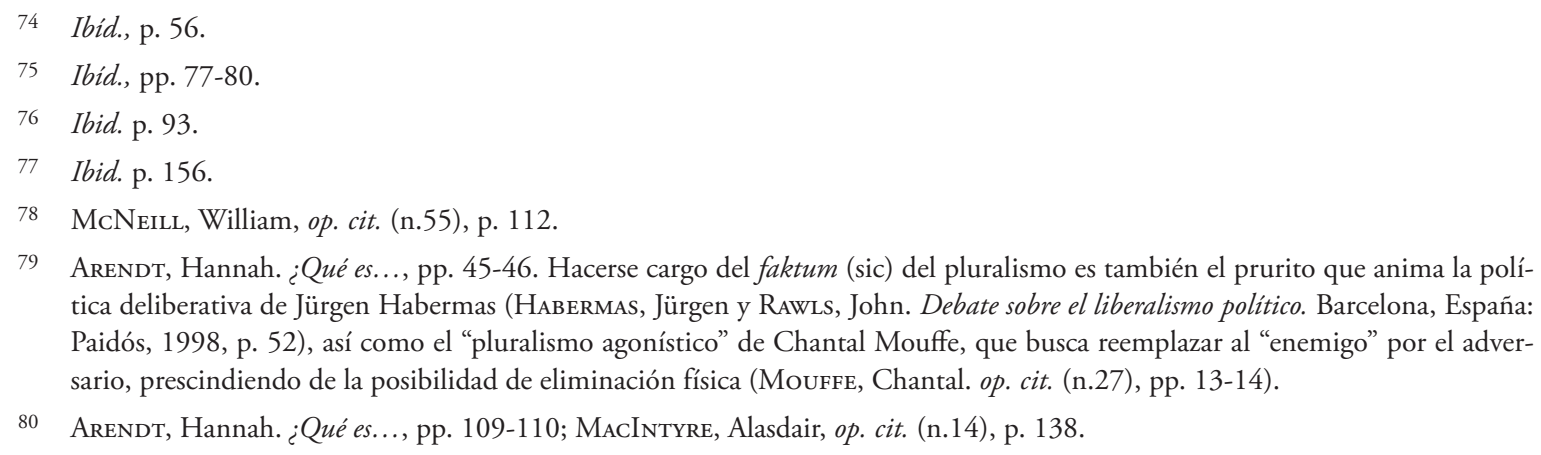
tica deliberativa de Jürgen Habermas (Habermas, Jürgen y Rawls, John. Debate sobre el liberalismo político. Barcelona, España: Paidós, 1998, p. 52), así como el "pluralismo agonístico" de Chantal Mouffe, que busca reemplazar al "enemigo" por el adversario, prescindiendo de la posibilidad de eliminación física (Mouffe, Chantal. op. cit. (n.27), pp. 13-14).

80 Arendt, Hannah. ¿Qué es..., pp. 109-110; MacIntyre, Alasdair, op. cit. (n.14), p. 138. 


\section{EL ADVENIMIENTO DE ULISES}

" $Y$ con ingenios se apodera de la campera fiera montaraz, y unciendo su cerviz al yugo, sujeta al corcel de cuello melenudo $y$ al toro infatigable de los montes. (...)

Con su capacidad de inventar artes, ingenioso más de lo que se pudiera esperar, a veces al mal, otras al bien se dirige". SÓFOCLES, Antígona.

Así como según Habermas la acción estratégica (orientada al éxito) es parasitaria de la acción comunicativa ${ }^{81}$ (orientada al entendimiento), para MacIntyre la astucia sólo podía operar en las sociedades heroicas ahí donde el valor fallaba ${ }^{82}$. Tal es la razón por la que la ofrenda del caballo de Troya, acto lindante entre la estratagema y la perfidia ${ }^{83}$, no es ni siquiera mencionada en La Ilíada, sino en el poema de la astucia, La Odisea ${ }^{84}$.

¿Por qué hoy nos parece tanto más deseable la forma de librar la guerra de Ulises? ¿Por qué la lectura de La Odisea nos resulta más atractiva que la de La Ilíada? ¿Qué sucedió con el paradigma antiguo de violencia comunicativa? ¿Ubi sunt Aquiles?

\section{I. LA GRAN TRANSFORMACIÓN}

Habermas acusa en su Teoría y praxis cómo evolucionó la política aristotélica hasta convertirse en la "filosofía social" de Hobbes ${ }^{85}$. Esta evolución comprende el desplazamiento de la antigua phronesis por la episteme, así como de la praxis por la technés. Un hito en el largo camino transitado es la infortunada traducción de Santo Tomás del zoon politikon de Aristóteles como animal sociale, por cuanto la societas es una simple federación por interés propio en que

81 Así como el sarcasmo es parasitario del lenguaje sincero. Véase HABERMAS, Jürgen. Conciencia..., p. 127.

82 MacIntyre, Alasdair, op. cit. (n.14), p. 123.

83 La "perfidia" es un término técnico en derecho humanitario, que consiste en aprovecharse de la buena fe del adversario mediante el recurso fraudulento a instituciones esencialmente protectoras, como la bandera blanca (art. 37 del Protocolo I Adicional a los Convenios de Ginebra). Si bien el caballo de Troya podría considerarse una estratagema, es decir, un acto lícito destinado a desorientar al enemigo, parece acercarse más al abuso de una seńal de confianza, como lo es una ofrenda de paz en realidad infestada de enemigos.

84 Entre otras hazañas de Ulises mañero, tales como su engaño al cíclope Polifemo (a quien le dijo "mi nombre es Ninguno"), o su pragmática decisión de pasar cerca de Escila en lugar de Caribdis, para sacrificar a unos cuantos de sus hombres en lugar de la perdición de toda la tripulación.

85 Habermas, Jürgen. Teoría y praxis. Madrid, España: Tecnos, 1997, p. 49.

86 Ibid., p.50. 
sus miembros "circulan por el lugar común como si estuvieran separados", a diferencia de la polis, en que los libres e iguales actúan y dialogan en conjunto orientados hacia la vida buena, y no sólo hacia la preservación de la vida", la "nuda vida" 88 o la "vida corriente" 89.

Tras Santo Tomás, Tomás Moro, con su prurito por erradicar el hambre, y Maquiavelo son las siguientes estaciones en el recorrido desde Aristóteles a Hobbes ${ }^{90}$. A juicio de Leo Strauss Maquiavelo inauguró la época de la "declinación de los estándares" en política, abandnando todo horizonte irrealizable de los antiguos para abocarse al análisis de las condiciones necesarias para asegurar la supervivencia ${ }^{91}$. Maquiavelo es, en definitiva, quien descubrió el continente sobre el que Hobbes erigiría su estructura política destinada a evitar la muerte violenta ${ }^{92}$.

Hasta aquí se han descrito cambios en la teoría política. ¿Qué hay de su presupuesto, la guerra? A pesar de lo que pudiera parecer a primera vista, la irrupción del arma de fuego (esa "desgraciada herramienta" al decir de Goethe) en Europa, alrededor del siglo XIV ${ }^{93}$, no provocó una revolución inmediata en la forma de librar la guerra. Como afirma Víctor Davis: "Cuando las armas de fuego entraron en escena, Europa, con mayor facilidad que otras culturas, transformó las filas de lanceros y piqueros en unidades de arcabuceros, que disparaban igual que habían lanceado y tajado, al unísono, a la orden, hombro con hombro y en formación"94. Por iguales razones Hegel se refiere al arma de fuego, en pleno siglo XIX, en particular a su descarga coordinada y frontal, como el medio a través del cual el valor personal se transforma en la expresión mecánica de un miembro de la totalidad ${ }^{95}$.

Lo anterior se explica porque, aún con el arma de fuego en ejercicio, el paradigma comunicativo de la guerra no fue desplazado de inmediato, sino que habría que esperar hasta la revolución norteamericana con sus tácticas de francotiradores, y la introducción del camuflaje en el ejército británico durante las guerras napoleónicas, para que se instalara el nuevo paradigma bélico ${ }^{96}$.

\footnotetext{
Ibid. p. 55. Arendt, Hannah. The human..., pp. 23; 37.

Agamben, Giorgio. Homo Sacer. El poder soberano y la nuda vida. I. Valencia, España: Editorial Pre-Textos, 1998, pp. 9-23.

TAYLor, Charles. Fuentes del yo: La construcción de la identidad moderna. Barcelona, España: Paidós, 1996, pp. 227-229.

Habermas, Jürgen, op. cit. (n.85), p. 58

91 Strauss, Leo. Natural right and history. Chicago, Estados Unidos: The University of Chicago Press, 1953, pp. $178 ; 191$. Strauss, Leo. ¿Qué es filosofía política? Madrid, España: Guadarrama, 1970, pp. 54; 64.

22 Strauss, Leo. Natural..., p. 177.

3 McNeill, William, op. cit. (n.55), p. 126

94 Davis, Víctor, op. cit. (n.56), p. 196. En contra, véase Jocelyn-Holt, Alfredo. Historia General de Chile. Tomo Uno: El retorno de los dioses. Santiago, Chile: Sudamericana, 2004, p. 278.

95 Hegel, G.W.F. Filosofía del Derecho. -5a ed.-, Buenos Aires, Argentina: Claridad, 1968, p. 273.

96 Jorgensen, Christer. Grandes Batallas. Los combates más trascendentes de la historia. Barcelona, España: Parragon, 2009, pp. 144-166.
} 
No obstante, los esfuerzos teóricos por cambiar el paradigma comunicativo de guerra (y por consiguiente el de política) precedieron a su práctica ${ }^{97}$. Es así como Hobbes postulaba un Estado que libraría a sus súbditos de la muerte violenta, a pesar de que las guerras todavía se luchaban con descargas de armas de fuego frente a frente con el enemigo. Es así como también Maquiavelo propugnaba una nueva manera de librar la guerra, propia del sujeto para quien escribía: el príncipe, quien debía saber comportarse como hombre y como bestia ${ }^{98}$. Maquiavelo aplicó la racionalidad estratégica (i.e., aquella que caracteriza a los sujetos que conciben a otros sujetos como medios para la consecución de sus fines, con la conciencia de que estos los consideran de la misma manera ${ }^{99}$ ) no sólo a los asuntos de gobierno, sino también a la guerra. Junto con propugnar la creación de un ejército nacional que no tuviera que depender de los mercenarios ${ }^{100}$, propuso que el príncipe no debía tener otro pensamiento fuera del arte de la guerra $^{101}$, estudiando la historia y entrenándose en la caza ${ }^{102}$. Maquiavelo había inaugurado un nuevo paradigma, de celadas, perfidia y asechanzas: el paradigma de la cacería, representado por Ulises, rico en ardides.

\subsection{A la caza del hombre}

Hasta aquí debería parecer evidente que lo que Maquiavelo inaugura teóricamente, y es aplicado incipientemente en la revolución norteamericana y las guerras napoleónicas, en tanto cacería, no puede ser considerado como "guerra", esto es, como hecho institucional. Ello por cuanto el paso simbolizador propio de un hecho institucional está totalmente olvidado en un modelo de asechanzas y celadas para sorprender al enemigo.

El cazador no requiere comunicar nada a su presa. Más aún, mientras menor sea la conciencia de la existencia del cazador por parte de la presa, mayores probabilidades de éxito tendrá aquél en la captura. El sigilo es el rasgo característico de una nueva forma de librar la guerra, que por lo tanto se ha extendido a una nueva forma de practicar la política, es decir, la acción estratégica $^{103}$. Se trata de un paradigma nuevo, al menos en occidente, pues si se analiza la obra

97 Esto puede presentar una dificultad lógica, pues ¿cómo puede cambiar el paradigma político primero, y luego el de la guerra, si la política es la continuación de la guerra? ¿Cómo puede ser el Maquiavelo político un punto de inflexión, si no lo es primero el Maquiavelo teórico de la guerra? Lo que se debe decir es que Maquiavelo es efectivamente un punto de inflexión, tanto en su teoría de la guerra como en su programa político, pero no es un cambio instantáneo, sino que es el comienzo de un proceso que se irradiaría hacia la práctica a lo largo de los siglos.

98 Maquiavelo, Nicolás. El Príncipe. Buenos Aires, Argentina: Gradifco, 2004, p. 107.

99 Apel, Karl Otto. Estudios Éticos. D.F., México: Editorial Fontamara, 2007, p. 36.

100 Maquiavelo, Nicolás, op. cit. (n.98), p. 79. Gaiada, María. "Maquiavelo, tratadista de la guerra. Vida civil y militar." Boletín del Centro Naval, 825: 207-216, septiembre/diciembre 2009, p. 211.

101 Maquiavelo, Nicolás op. cit. (n.98), p. 93.

102 Ibíd., p. 94.

103 Como se advierte, en la acción estratégica, si bien hay consideración a un "otro" dentro de la estrategia dominante, lo cierto es que los demás jugadores son tan sólo datos adicionales proporcionados por el mundo objetivo, concebidos, como cualquier otro objeto, como obstáculos a ser derribados, aunque dotados de particular resistencia en virtud de su inteligencia. 
milenaria El arte de la guerra de Sun Tzu, que data del siglo VI a.c., se encuentran diseminados por doquier los argumentos hoy imperantes en la práctica de la guerra y la política contemporáneas. Así declara Sun Tzu que: "El arte de la guerra se basa en producir señales falsas (...). Ataca al enemigo cuando no está preparado, y aparece cuando no te espera"104. Por lo anterior los espías son de vital importancia ${ }^{105}$, así como el combate repentino y veloz ${ }^{106}$, palabras que resuenan en el azote de la guerra del siglo XX, la "guerra relámpago" (blitzkrieg).

Ahora bien, como sucede con toda cacería, el cazador está sólo frente al mundo ${ }^{107}$. Lo único que hay en él son presas y herramientas (lo "a la mano" en Heidegger), como consecuencia del mentado desplazamiento de la praxis por la techné en el nuevo paradigma de cacería.

Para Heidegger la técnica es "desocultamiento", la introducción de lo que no estaba, mientras que la esencia de la técnica es la disposición constante del hombre a utilizarla, como su sujeto. El riesgo que conlleva la esencia de la técnica es que esa disposición del hombre se vuelva contra sí mismo, tornándolo en un objeto más de la técnica y aboliendo al sujeto de la misma ${ }^{108}$.

Esta objetivación del hombre es precisamente en lo que ha devenido la guerra, ahora como cacería, en que predominan las celadas, las añagazas, el camuflaje, la sorpresa, las armas de precisión, la mecanización, y como epítome, el terrorismo o "guerra contra el terror", que es una guerra que nunca se puede ganar y por tanto no termina ${ }^{109}$. El terrorismo, presente hoy tanto en la guerra convencional como en la guerra de guerrillas ${ }^{110}$, es el paradigma de la "guerra asimétrica" o aquella en que la igualdad de armas se ha perdido ${ }^{111}$ y las partes se ven envueltas en una carrera en declive hacia el uso de métodos pérfidos, en que cada quien es a la vez cazador y presa ${ }^{112}$.

\footnotetext{
104 Tzu, Sun. El arte de la guerra. Buenos Aires, Argentina: Gradifico, 2008, pp. 12-14.

105 Ibid., pp. 87-94.

106 Ibid., pp. 17; 39.

107 Aún si se piensa en una empresa cooperativa de cacería, tomar la vida de un animal no puede equivaler a contribuir a la deuda de la que todos somos codeudores solidarios, tomando la vida de otro hombre. Por lo demás, la comunicación entre cazadores se limita a lo estrictamente necesario para no romper el sigilo necesario para el acecho, y en ningún caso se comunican con la presa.

108 Heidegger, Martin. Filosofía, ciencia y técnica. Santiago, Chile: Editorial Universitaria, 2004, p. 143.

109 SLoterdijk, Peter, op. cit. (n.8), p. 219.

110 Walzer, Michael, op. cit. (n.6), p. 241.

111 Pfanner, Toni. La guerra asimétrica desde la perspectiva de la acción y el derecho humanitarios. Revista Internacional de la Cruz Roja, 857: 149-174, marzo 2005, pp. 150 y ss.

112 Según Negri y Hardt la guerra contra el terrorismo no es sino la evolución del arte de la guerra en "arte de la policía". Véase Hardt, Michael y Negri, Antonio. La multitud y la guerra. Santiago, Chile: LOM, 2008, p. 25.
} 


\title{
4.EL REGRESO DE ENEAS
}

\author{
“Amigos! ;Sed hombres y aprestad vuestro \\ fornido corazón! Teneos mutuo respeto en \\ las esforzadas batallas: de los que se \\ respetan, más se salvan que sufren la \\ muerte; $y$ de los que huyen, ni se alza \\ la gloria ni ningún auxilio". \\ Homero, La Ilíada.
}

Simone Weil afirma que la única verdadera épica de occidente está en La Ilíada, siendo La Odisea y La Eneida sólo malas imitaciones ${ }^{113}$. Sin embargo, Hannah Arendt sostiene que los griegos y los romanos eran pueblos gemelos precisamente porque compartían un mismo mito fundante ${ }^{114}$, que no se agotaba en La Ilíada, sino que encuentra su epílogo en La Eneida. Cuando Eneas conduce a su gente hacia tierras italianas para refundar Troya, vence a Turno y se une en matrimonio con la hija del rey Latino, condonando su insurgencia, no sólo está fundando el linaje de Rómulo y Remo, sino que está preservando al pueblo derrotado por los aqueos (griegos). Pero así como la agôn es constitutiva del genio griego, el perdón lo es del carácter romano ${ }^{115}$, en la forma del derecho y de la alianza. Pues los romanos no se recluían, como los griegos, tras la victoria en las murallas de sus polis, sino que reconocían al enemigo como un aliado, extendiendo la liza (arena política y de batalla), mediante el derecho (el ius gentium). Y así lo hicieron con quienes los habían derrotado siglos atrás, los griegos ${ }^{116}$.

\section{I. LA REgULACión DE LA GUERRA}

Cuando se piensa en normas de la guerra, lo primero que viene a la mente, a la luz de las terribles carnicerías del siglo XX, es la frase de Lévinas, para quien "la guerra torna a la moral en algo irrisorio". Sin embargo, la hilaridad que el postulado de la regulación de la guerra inspira en verdad es producto del desplazamiento del paradigma de Aquiles por el de Ulises, pues en la cacería no puede haber más regulación que meras directrices técnicas ${ }^{117}$. Como espetan los atenienses a los habitantes de Melos: “(...) en las cuestiones humanas las razones de derecho in-

113 WeIL, Simone, op. cit. (n.10), p. 27.

114 Arendt, Hannah. ¿Qué es..., p. 115.

115 Incluso Fustel De Colulanges presenta a Eneas, el piadoso, como un "sacerdote". De Coulanges, Fustel. La Ciudad Antigua. -10a ed-. Madrid, España: Edaf, 2007, p. 136.

116 Arendt, Hannah. ¿Qué es..., p. 119. Birmingham, Peg. On Violence, Politics and the Law. Journal of Speculative Philosophy, 24(1): 1-20, 2010, p. 17.

117 Sobre la diferencia entre reglas constitutivas y directrices, véase Von Wright, Georg. Norma y Acción. Madrid, España: Tecnos, 1979, pp. 21-35. 
tervienen cuando se parte de una igualdad de fuerzas, mientras que, en caso contrario, los más fuertes determinan lo posible y los débiles lo aceptan"118. Es por eso que no puede haber "reglas de la cacería”, pues cazador y presa nunca serán iguales.

En este momento es pertinente retornar a un punto pendiente en el análisis de la guerra como hecho institucional. Como se dijo, el hecho institucional importa un paso simbolizador, pero también uno deóntico. Y ese nuevo "deber ser" es más que la mera resistencia que el mundo (el hecho bruto) ofrece en primer lugar. Es consecuencia de una convención, que transforma el mundo, y que sólo puede suceder y valer entre sujetos que se reconocen agencia comunicativa y moral, y adoptan un compromiso. Como dice Nietzsche, el hombre no es el único animal capaza de reír, sino también es el animal "que tiene el derecho de prometer"119. Es por eso que la guerra, qua hecho institucional, por definición admite regulación, no así la cacería.

\subsection{De iURe Belli}

Si se acepta que la guerra es un hecho institucional y por tanto generador de deberes, tales obligaciones pueden perfectamente adoptar la forma del derecho, y no sólo de la moral ${ }^{120}$. Siguiendo a la "jurisprudencia de New Haven" del derecho internacional, representada por Harold Laswell y Myers McDougal, se puede decir que el derecho es el resultado de un proceso político de poder, y consiste en un fenómeno de autoridad (validez) y control (eficacia) ${ }^{121}$.

Pero si el derecho es el resultado de la política, y la política es a su vez la continuación de la guerra, entonces el derecho en último término tiene su origen en la guerra ${ }^{122}$. Y si la guerra es un hecho institucional portador de un contenido deóntico, y el derecho es también un hecho institucional (como afirma Searle), entonces el derecho en realidad es un hecho institucional contenido dentro de otro, la guerra. Es aquí donde radica toda esperanza para restablecer el paradigma de Aquiles, mediante el nuevo paradigma de Eneas piadoso, que devolverá a la cacería su carácter humano. Por cuanto mediante el derecho, a la manera romana, se puede reconocer al enemigo una igualdad mínima fundante de un respeto recíproco, extendiendo la liza, que en la guerra adopta la forma del derecho internacional humanitario (que protege a los heridos,

\footnotetext{
118 Tucídides. Historia de la Guerra del Peloponeso. Libro V. Madrid, Espańa: Gredos, 1992, p. 143.

119 HöFFE, Otfried. El proyecto político de la modernidad. Buenos Aires, FCE, 2008, p. $91 .$.

120 Aquí se adhiere a la diferencia entre derecho y moral postulada por Tomassio y Kant, esto es, el ámbito de adjudicación, siendo externo en el derecho y ante el tribunal de la propia conciencia en la moral.

121 Norton, John. Prolegomenon to the jurisprudence of Myers McDougal and Harold Laswell. Virginia Law Review, 54: 662688, 1968, p. 666. Schmitt coincide con este análisis, al decir que la "ley constitucional" (la constitución legal) es el resultado de un proceso político previo que culmina en una decisión acerca de la forma y modo de existencia de la unidad política, o "constitución". Véase Sснмiтt, Carl. Teoría de la Constitución. Madrid, España: Alianza, 2001, p. 46.

122 De ahí la caracterización del derecho por Benjamin como resultado del ejercicio de la violencia mítica. Benjamin, Walter, op. cit. (n.11), p. 23.
} 
prisioneros y civiles), y en la política la forma de los derechos humanos. Estos dos sistemas son diferentes, pero complementarios ${ }^{123}$, pues mientras aquél está llamado a regir sólo en tiempos de conflicto, éste es el que rige siempre a lo menos.

Por supuesto, el peligro estriba, como advierte Thomas Smith, en terminar recurriendo al derecho para legitimar maneras cada vez más sofisticadas de cacería, volviéndose el derecho tansólo una herramienta más de la techné ${ }^{124}$. Pero ello no debería suceder si se rescata el carácter de hecho institucional del derecho, así como de la guerra, que es lo que sucede "entre hombres", no entre homo faber y technél25.

Por otro lado, el derecho es sólo una parte del carácter deóntico de la guerra, pues como se dijo, la "convención de la guerra", reflejo de su realidad moral, incluye todos los juicios normativos acerca de la misma, condensados en la tradición de la Guerra Justa.

\subsection{La tradición de la Guerra Justa}

Según Michael Walzer, siempre juzgamos la guerra dos veces. Primero, adjetivamente, al calificar las razones para iniciarla, o ius ad bellum. Segundo, adverbialmente, al enjuiciar la manera de conducir las hostilidades, o ius in bello ${ }^{126}$. Estas valoraciones, en constante debate y evolución, constituyen la tradición de la Guerra Justa.

Si bien pueden rastrearse argumentos para la regulación de la guerra hasta Platón y Aristóteles, es con los romanos que la tradición de la Guerra Justa comienza a configurarse como tal, debido a su desiderátum de justificar jurídicamente la guerra ${ }^{127}$.

Fueron Platón y Cicerón los primeros en sostener que lo que se debía buscar con la guerra era la paz (si vis pacem, para bellum). Más tarde San Agustín reitera esta idea ${ }^{128}$. Cicerón además hizo hincapié en la declaración de la guerra (ius fetiale) por parte de la autoridad correspondiente. Luego Santo Tomás de Aquino condensaría estos requisitos para una Guerra Justa

123 Swinarsky, Christophe. Derecho internacional humanitario como sistema de protección de la persona humana en su relación con el derecho internacional de los derechos humanos. En: Fraidenraij, Susana y MÉndez, Ricardo (comp.). Elementos de derecho internacional humanitario. D.F., México: UNAM, 2001, p. 56.

124 SMITH, Thomas. The New Law of War: Legitimizing Hi-Tech and Infrastructural Violence. International Studies Quarterly, 46: 355-374, 2002, p. 356. Otro peligro reside en legitimar la guerra de dominación emprendida por el “imperio" (EE.UU.), bajo el pretexto de que es una "guerra justa", como sostienen Negri y Hardt. Inlcuso creen que el concepto de "la política como la continuación de la guerra por otros medios" es una herramienta imperial de aherrojamiento. No obstante, esta conducción meramente estratégica de la guerra debería poder remediarse con el requisito de la recta intención. Véase HARDT, Michael y NEGRI, Antonio, op. cit. (n.112), pp. 23; 127.

125 Sobre la relación entre guerrea y techné véase MEILEANDER, Gilbert. War and Techne. The New Atlantis: 45-53, verano 2003, p. 49.

126 Walzer, Michael, op. cit. (n.6), p. 43.

127 Bellamy, Alex, op. cit. (n.4), pp. 44-47.

128 Ibid., p. 58. 
en: autoridad legítima, justa causa, recta intención ${ }^{129}$. También introdujo la doctrina del "doble efecto", es decir, aquella que justifica la guerra en la medida que los efectos adversos de ésta no sean buscados intencionalmente, ni tampoco sean un medio para la consecución de fines lícitos, y en todo caso los beneficios que se obtengan sean mayores que los perjuicios (proporcionalidad según Sidgwick) $)^{130}$.

Más adelante Francisco Vitoria sostuvo que las únicas causas justas eran la reivindicación de una ofensa, la legítima defensa y la protección del inocente ${ }^{131}$, además de plantear lo que Turner ha llamado la "justicia simultánea ostensible" (i.e. la posibilidad de que ambas partes estén en lo correcto ${ }^{132}$ ). Vitoria también introdujo el requisito de la necesidad, cuando otras vías fallan. Hugo Grocio reitera las nociones de autoridad legítima, causa justa (reivindicación de una injuria, legítima defensa, retribución o castigo y recuperación de lo usurpado) y recta intención ${ }^{133}$. Incluso Kant realiza un singular aporte a la tradición, con su ius post bellum ${ }^{134}$.

Como manifestaciones del desplazamiento del ius ad bellum al ius in bello en el siglo XIX, consecuencia de la "justicia simultánea ostensible"135, destacan la creación de la Cruz Roja ${ }^{136}$ (1864), y la codificación de la normativa consuetudinaria para el comportamiento en combate en el Código Lieber (1863), para el ejército de los EE.UU.

Por último, el ius in bello adoptó la forma del derecho internacional humanitario ${ }^{137}$, o aquella rama del derecho internacional dedicada a regular la conducción de las hostilidades

129 Aquino, Tomás de. Suma Teológica. Vol. 2. Secunda secundae, Quaestio XL. Madrid, España: Editorial Católica S.A., 1959, pp. 1075-1076.

130 Lo que en derecho penal se conoce como el "voluntario indirecto". Véase Bellamy, Alex, op. cit. (n.4), p. 74. Walzer, Michael, op. cit. (n.6), p. 192.

131 Bellamy, Alex, op. cit. (n.4), p. 95.

132 Ibid., pp. 96.

133 Grocio, Hugo, op. cit. (n.15), pp. 145; 258-259; 279.

134 Kant, Immanuel. La paz perpetua. Madrid, España: Tecnos, 1998, pp. 5-69; Orend, Brian. Kant's Just War Theory. Journal of the History of Philosophy, 37(2): 323-353, abril 1999.

135 Bellamy, Alex, op. cit. (n.4),p. 98.

136 Su fundador, Henry Dunant, describe la batalla que le inspiró a crear esta organización: "Austríacos y aliados se pisotean, se matan unos a otros sobre cadáveres que sangran, intercambian contundentes culatazos, se destrozan el cráneo, se destripan a sablazos o a bayonetazos; ya no hay cuartel, es una matanza, un combate de animales feroces, rabiosos y ebrios de sangre (...). Con los relinchos de los caballos se mezclan vociferaciones, gritos de rabia, alaridos de dolor y de desesperación. Aquí, pasa la artillería a todo correr, siguiendo a la caballería; se abre camino por entre los cadáveres y los heridos que, promiscuamente, yacen por tierra: así, se vacían cráneos, se rompen y se descoyuntan miembros, el suelo se empapa de sangre y la llanura está cubierta de despojos humanos”. Dunant, Henry. Recuerdo de Solferino. <En línea>. [Citado 28 junio 2011] Disponible en la Web <http://www.icrc.org/WEB/SPA/sitespa0.nsf/htmlall/p0361/\$File/ICRC_003_P0361.PDF>, p. 4.

137 Cuyos principios clásicos son la "caballerosidad", la "necesidad militar" (medidas necesarias para obtener ventajas militares lícitas) y la "humanidad" o "distinción" (entre soldados y civiles, art. 48 Protocolo I). Véase Doswald-Beck, Louise y Vité, Sylvain. Derecho internacional humanitario y derecho de los derechos humanos. Revista Internacional de la Cruz Roja, 116: 99-126, marzo-abril 1993, p. 99. También se agrega el principio de la "proporcionalidad" entre costos y beneficios, para morigerar el principio de necesidad. Véase WALZER, Michael, op. cit. (n.6), p. 165. 
("derecho de La Haya", desde 1899) y el trato a los prisioneros, heridos y civiles ("derecho de Ginebra" desde 1929) ${ }^{138}$, consolidado como tal en los Protocolos Adicionales a las Convenciones de Ginebra de 1949, en 1977.

En suma, los requisitos que la tradición postula para calificar a una guerra como justa son: justa causa (incluyendo legítima defensa, protección de derechos, reivindicación de una injuria o usurpación), recta intención (buscar la paz y el bien común), autoridad legítima, necesidad o último recurso, y proporcionalidad (entre costos y beneficios) ${ }^{139}$.

A pesar de la tendencia al ius contra bellum ya mencionada, en la primera mitad del siglo $\mathrm{XX}$, en la Carta de la ONU no se abolió completamente la Guerra Justa, sino por el contrario, los requisitos mencionados se encuentran recogidos en ese instrumento. Tal es el caso de la legítima defensa y el respeto a los derechos humanos como justa causa (art. 51; art. 1.2), la autoridad legítima (Consejo de Seguridad, cap. VII), la recta intención (art. 1.1), la necesidad y la proporcionalidad (arts. 39-42).

Es por lo anterior que puede decirse que el crimen de agresión en realidad se configura como una "guerra injusta", esto es, una guerra que no satisface los requisitos de la Guerra Justa cristalizados en la Carta de la ONU, no siendo sino la más reciente aportación al discurso milenario de la Guerra Justa.

\subsection{EXCURSO SOBRE LA CONTINGENCIA: INTERVENCIÓN HUMANITARIA}

Carl Schmitt afirma: "Quien dice humanidad quiere engañar"140. Con esto se refiere a que, dado que lo político siempre presupone un amigo y un enemigo, quienes aducen razones de humanidad intentan sustraerse de la dimensión de lo político, hacia lo indiferenciado que representa la humanidad (no hay "enemigos de la humanidad", pues todos somos humanos). Una intervención humanitaria sería, por tanto, un acto de engaño, de embozamiento de lo político, en la forma de una "guerra civil internacional".

Sin embargo, Schmitt opera sobre la base del paradigma de la cacería, plenamente consolidado al tiempo en que escribió su obra (entre las dos grandes guerras cuyo coto de caza se extendió a todo el planeta), y por eso no puede aceptar reconocimiento alguno entre enemigos, pues ¡cómo reconocer a la presa?

138 Moreno del Cueto, Carmen. La importancia de los Convenios de Ginebra en la evolución del derecho internacional público. En: Fraidenraij, Susana y Méndez, Ricardo (comp.). Elementos de derecho internacional humanitario. D.F., México: UNAM, 2001, pp. 21-24.

139 Bellamy los clasifica en criterios sustanciales (recta intención, justa causa, proporcionalidad, necesidad), prudenciales (razonable expectativa de éxito) y procesales (autoridad legítima y declaración). Bellamy, Alex, op. cit. (n.4), pp. 191-194.

140 Sснміт, Carl. El concepto..., p. 201. 
Pero si se adopta el paradigma comunicativo de Aquiles, remozado por la figura de Eneas, perfectamente se puede concebir el reconocimiento del enemigo, y ello es comprendido por una neo-schimittiana como Chantal Mouffe, con su "pluralismo agonístico" (que busca reemplazar al enemigo por el adversario $\left.{ }^{141}\right)$. Ello por cuanto existe un sustrato de igualdad que trasciende la mera eliminación recíproca, y que proviene de nuestra calidad de codeudores solidarios ante la muerte, que nos iguala y es condición de posibilidad de la extensión de la liza (bélica y política) que caracteriza al nuevo paradigma comunicativo. Schmitt es ciego a este reconocimiento porque, desde el coto de caza, sólo puede divisar el hecho bruto de "comerse los unos a los otros".

Pues bien, en base a ese reconocimiento, fundado en la igualdad ante la muerte, la liza puede extenderse en la forma jurídica del derecho humanitario y los derechos humanos. Cuando alguien intenta abolir ese reconocimiento violando sistemáticamente y a gran escala los derechos humanos, aún a nivel interno, es deber de los demás agentes el reivindicar esos derechos, lo cual es una de las justas causas dentro de la tradición de la Guerra Justa. Tal es el caso de la actual intervención humanitaria en Libia (autorizada por la resolución 1973 del Consejo de Seguridad ${ }^{142}$ ), ante la cual Noam Chomsky es escéptico, aunque no por eso deja de creer en general en las intervenciones humanitarias ${ }^{143}$

Sobre este punto, Bellamy destaca que existe un deber de consecuencia para los países que en determinados momentos han decidido intervenir humanitariamente (Kosovo), pero que han dejado de hacerlo en situaciones de similares características (Darfur, Sudán). Bellamy ${ }^{144}$ se refiere a los criterios establecidos por la Comisión Internacional sobre Intervención y Soberanía, de los que emana la "responsabilidad de proteger", y que incluyen como justa causa las matanzas y limpiezas étnicas, es decir, violaciones masivas de derechos humanos ${ }^{145}$. A ello se agrega la recta intención (materializada en la intervención consecuente, en toda ocasión), necesidad, proporcionalidad y razonables expectativas de éxito. Bellamy agrega que la autoridad legítima debe ser primero el Estado huésped, luego el Consejo de Seguridad de la ONU, luego organizaciones regionales (como la OTAN), y sólo en subsidio de todos ellos Estados que actúen por cuenta propia ${ }^{146}$.

Ahora bien, ¿qué es aquello que se reconoce en el enemigo y en los no combatientes, ya en la guerra, ya en lo político, que justifica una intervención? Se trata de una igualdad en un

\footnotetext{
141 Mouffe, Chantal. op. cit. (n.27), p. 16.

142 Precedida por la condena al régimen libio de parte de la Unión Africana, la Liga de Estados Árabes y la Organización de la Conferencia Islámica.

143 En particular, destaca la intervención de India contra Pakistán en Bangladesh en 1971, y de Vietnam en contra de Camboya en 1978. Véase Chomsky, Noam. On Libya and the Unfolding Crises (entrevista). <En línea>. [Citado 28 junio 2011] Disponible en la Web: <http://www.zcommunications.org/noam-chomsky-on-libya-and-the-unfolding-crises-by-noam-chomsky>, p. 3.

144 Bellamy, Alex, op. cit. (n.4), p. 339.

145 Coincidiendo con Walzer, quien agrega además como justa causa la liberación nacional y la contraintervención. WALZER, Michael, op. cit. (n.6), p. 121.

146 Bellamy, Alex, op. cit. (n.4), pp. 315-325.
} 
sentido adicional al de la solidaridad ante la muerte; es una igualdad en dignidad, entendida no sólo como "valor en lugar de precio" (Kant), sino como status, elevación de rango de todos los seres humanos, para el trato recíproco como si se tratase siempre de relaciones entre nobles, como propone Jeremy Waldron ${ }^{147}$. Noblesse oblige.

La intervención humanitaria busca reafirmar esa dignidad, esa igualdad, y se configura como "ira justa" frente a la falta de reconocimiento. Pero más importante aún, se trata del resabio del código de caballería medieval, en que los caballeros no sólo reconocían a su enemigo (de ahí el saludo militar, como ademán para levantar la visera del yelmo), sino también protegían a quienes no podían defenderse ${ }^{148}$. Es la razón por la que MacArthur pudo reprochar al general Yamashita ${ }^{149}$ : "El soldado, sea amigo o enemigo, tiene a su cargo la protección de los débiles e inermes. Es la verdadera razón y esencia de su ser, una misión sagrada"150. Es el motivo también por el cual la figura del "soldado desnudo", el inerme, suscita un momento de reconocimiento y conmiseración en los hombres de armas ${ }^{151}$.

Que se utilice la intervención humanitaria sin recta intención, como hizo el mismo Hitler para invadir Checoslovaquia ${ }^{152}$, no hace sino confirmar las palabras de Schopenhauer: "las cosas más sublimes son las que se corrompen de la peor manera”.

La intervención humanitaria revitaliza el código de caballería, como proponen DoswaldBeck y Vité, en la medida en que se forme un ethos militar de respeto a los derechos humanos, tanto del adversario cuanto de los no combatientes, tras la pérdida del ethos cristiano de caballerosidad que en el medioevo cohesionaba a los hombres de armas y a los civiles ${ }^{153}$.

Por último, cabe señalar que antes de la definición de Kampala Christopher De Nicola propugnó la inclusión de un "escudo para los caballeros de la humanidad" en el artículo 8bis, esto es, una causal de justificación para el crimen de agresión con base a una necesidad de intervención humanitaria ${ }^{154}$. Como se sabe, tal causal de justificación no fue incluida en Kampala, y más aún, el artículo 5.1 de la resolución 3314, que inspiró el nuevo artículo 8bis, parece excluir

147 WALdRon, Jeremy. Dignity, rank and rights (Tanner Lectures). Marzo, 2009, pp. 15-16.

148 El caballero promete "tener lealtad y rectitud ejemplar, ser protector de los pobres, sostén de los débiles, defensor de las mujeres", y cree sobre todo que "una persona no está obligada a obedecer a una amenaza, a una orden que sobreponga los límites de lo que es compatible con la dignidad del hombre libre". Véase Zorrila, Enrique. La Cristiandad Medieval y su Espiritu Guerrero Caballeresco. Santiago, RIL Editores, 2000, pp. 61-69; 121.

149 Debido a los actos cometidos por fuerzas japonesas en Filipinas en 1945.

150 Walzer, Michael, op. cit. (n.6), p. 376.

151 Walzer señala cómo George Orwell describió su encuentro con el "soldado desnudo" en la guerra civil española: “(...) Yo había venido para tirar contra 'fascistas', pero un hombre que se sostiene los pantalones no es un 'fascista', es visiblemente un congénere, un semejante y uno no siente deseo de tirar contra él". Véase Ibid., p. 177. También sobre el "soldado desnudo" y el reconocimiento véase Meileander, Gilbert, op. cit. (n.125), p. 48.

152 Brownlie, Ian. International Law and the use of force by States. Oxford, Reino Unido: Clarendon Press, 1963, pp. 339-340.

153 Véase Doswald-Beck, Louise y Vité, Sylvain, op. cit. (n.137), p. 126.

154 De Nicola, Christopher, op. cit. (n.3) pp. 680 y ss. 
la posibilidad de la intervención humanitaria ${ }^{155}$. Sin embargo, hay quienes, como Fernando Tesón ${ }^{156}$, interpretan la definición de la agresión (tanto de 1974 como de 2010) de manera que se pueda incluir la intervención humanitaria, como quiera que la acción prohibida debe ser incompatible con la Carta de la ONU, mientras que la intervención humanitaria la reafirma en su desiderátum por respetar los derechos humanos, contenido en el art. 1.3 de la Carta.

\section{CONCLUSIÓN}

"La guerra es el infierno", es el apotegma proferido por el general William Sherman durante la guerra civil norteamericana, cuando tuvo que justificar el bombardeo de la ciudad de Atlanta.

La tradición de la Guerra Justa, de la cual el crimen de agresión no es sino la más reciente contribución, discurre entre Escila y Caribdis. De un lado, el realismo, es decir, el escepticis$\mathrm{mo}^{157}$. De otro, el pacifismo, esto es, la candidez ${ }^{158}$. El primero no comprende el hecho institucional de la guerra, y por tanto lo reduce al hecho bruto de la cacería. El segundo no puede dar cuenta del factum eterno de la violencia en los fenómenos humanos ${ }^{159}$, y si desea hacerlo tiene la carga de la prueba de contravenir 200.000 años de existencia humana, pues "sólo los muertos han visto el fin de la guerra” (Platón).

Si Aristóteles está en lo correcto, y el hombre es en esencia un zoon politikon ${ }^{160}$, y si, como se ha demostrado, la política es la continuación de la guerra por otros medios, entonces es necesario dar la razón al dictum de Heráclito: "la guerra es el padre de todas las cosas", o cuando menos de todas las cosas que son propiamente humanas ${ }^{161}$.

Lo anterior no equivale a hacer una apología de la guerra ${ }^{162}$, en parte porque lo que hoy se entiende por una apología tal es en realidad una defensa del paradigma de la cacería. Pero además porque cuando se intenta, como en la presente reflexión, reivindicar un paradigma antiguo de violencia comunicativa, en que es posible el reconocimiento mediante la extensión de

\footnotetext{
155 Art. 5.1: Ninguna consideración, cualquiera sea su índole, política, económica, militar o de otro carácter, podrá servir de justificación de una agresión.

156 O’Connor, Laurie, op. cit.. (n.3), p. 11.

157 Como el de Maquiavelo, Sherman, Lévinas y Aron.

158 Sobre el pacifismo véase el "militarismo pacifista" de Max Scheler (Scheler, Max. El puesto del hombre en el cosmos. La idea de paz perpetua y el pacifismo. Barcelona, Espańa: Alba Editorial, 2000, pp. 130-203), y el pacifismo jurídico de Eduardo Salazar (SalazAr, Eduardo. Violencia, Agresión y Guerra. Santiago, Chile: Ediciones Ercilla, 1943).

159 Factum del que sí se hacen cargo Hannah Arendt y Chantal Mouffe. Véase Birmingham, Peg. Op. cit., p. 4. Mouffe, Chantal. op. cit. (n.27), p. 12.

160 "Los hombres" diría Hannah Arendt.

161 Arendt, Hannah. ¿Qué es..., p. 117.

162 Como la emprendida por Clausewitz, Hegel y De Maistre, para quienes la guerra previene la putrefacción inherente al estancamiento de la paz y la comodidad. Von Clausewitz, Karl, op. cit. (n.18), p. 121. Hegel, G.W.F, op. cit. (n.95), p. 270. De Maistre, Joseph, op. cit. (n.22), pp. 32-34.
} 
la liza, en base a la igualdad en dignidad y ante la muerte, lo que se busca es devolver a la guerra su condición institucional, su carácter propiamente humano. Sólo de esta manera se pueden entender en plenitud las palabras de R.W. Emerson:

"La guerra educa los sentidos, llama a la voluntad a la acción, perfecciona la constitución física, lleva a los hombres a tal rápida y cercana colisión en momentos criticos que el hombre es la medida del hombre".

\section{REFERENCIAS BIBLIOGRÁFICAS}

Agamben, Giorgio. Homo Sacer. El poder soberano y la nuda vida. I. Valencia, España: Editorial Pre-Textos, 1998.

Apel, Karl Otto. Estudios Éticos. D.F., México: Editorial Fontamara, 2007.

Arendt, Hannah. ¿Qué es política? Barcelona, España: Paidós, 1997. . Sobre la violencia. Madrid, España: Alianza Editorial, 2006. The human condition. Chicago, Estados Unidos: The University of Chicago Press, 1958.

Aquino, Tomás de. Suma Teológica. Vol. 2. Secunda secundae, Quaestio XL. Madrid, España: Editorial Católica S.A., 1959.

Bellamy, Alex. Guerras Justas. De Cicerón a Irak. Buenos Aires, Argentina: Fondo de Cultura Económica, 2009.

Benjamin, Walter. Para una crítica de la violencia. Buenos Aires, Argentina: Editorial Leviatán, 1995.

Birmingham, Peg. On Violence, Politics and the Law. Journal of Speculative Philosophy, 24(1): 1-20, 2010.

Brownlie, Ian. International Law and the use of force by States. Oxford, Clarendon Press, 1963.

Bugnion, Francois. Guerra justa, guerra de agresión y Derecho Internacional Humanitario, en: Revista Internacional de la Cruz Roja, 847: 523-546, 2002.

Сномкку, Noam. On Libya and the Unfolding Crises (entrevista). <En línea>. [Citado 28 junio 2011] Disponible en la Web: <http://www.zcommunications.org/noam-chomsky-on-libya-and-the-unfolding-crises-bynoam-chomsky>.

Clastres, Pierre. Arqueología de la violencia: la guerra en las sociedades primitivas. 2a ed., Buenos Aires, Argentina: Fondo de Cultura Económica, 2009.

DAvis, Victor. Matanza y cultura. Batallas decisivas en el auge de la civilización occidental. D.F:, México: Fondo de Cultura Económica, 2006.

De Coulanges, Fustel. La Ciudad Antigua. io a ed. Madrid, España: Edaf, 2007.

De Maistre, Joseph. Consideraciones sobre Francia. Madrid, España: Tecnos, 1990.

De Nicola, Christopher. A shield for the "Knights of Humanity": The ICC should adopt a humanitarian necessity defense to the crime of aggression, en: University of Pennsylvania International Law Review, 30(2): 641-689, 2008.

Doswald-Beck, Louise y Vité, Sylvain. Derecho internacional humanitario y derecho de los derechos humanos, en: Revista Internacional de la Cruz Roja, 116: 99-126, marzo-abril 1993.

Dunant, Henry. Recuerdo de Solferino. <En línea>. [Citado 28 junio 2011] Disponible en la World Wide Web: <http://www.icrc.org/WEB/SPA/sitespa0.nsf/htmlall/p0361/\$File/ICRC_003_P0361.PDF>.

Durán, Roberto. Las relaciones internacionales en la concepción de Raymond Aron. <En línea>. [Citado 28 junio 2011] Disponible en la World Wide Web: <http://www.uc.cl/icp/revista/pdf/rev61/ar2.pdf>. 
Foucault, Michel. Defender la sociedad. -2a ed.-, D.F., México: Fondo de Cultura Económica, 2006.

GaiAda, María. Maquiavelo, tratadista de la guerra. Vida civil y militar. Boletín del Centro Naval, 825: 207-216, septiembre/diciembre 2009.

Grocio, Hugo. Del derecho de la Guerra y de la paz, Tomo I Madrid, España: Editorial Reus, 1925.

Habermas, Jürgen y Rawls, John. Debate sobre el liberalismo politico. Barcelona, España: Paidós, 1998.

Habermas, Jürgen. Conciencia moral y acción comunicativa. Barcelona, España: Península, 1983.

Facticidad y validez. Sobre el derecho y el Estado democrático de derecho en términos de teoría del discurso. -4a ed-. Madrid, Espańa: Trotta, 2005.

Teoría de la acción comunicativa, I. Madrid, España: Taurus, 1981.

Teoría de la acción comunicativa. Complementos y estudios previos. Madrid, España: Cátedra, 1984.

Teoría y praxis. Madrid, Tecnos, 1997.

Verdad y justificación. Madrid, España: Trotta, 2002.

Hardt, Michael y Negri, Antonio. La multitud y la guerra. Santiago, Chile: LOM, 2008.

Hegel, G.W.F. Filosofía del Derecho. 5a ed., Buenos Aires, Argentina: Claridad, 1968.

Heidegger, Martin. El ser y el tiempo. -2a ed.- Buenos Aires, Argentina: Fondo de Cutlura Económica, 2010.

Filosofía, ciencia y técnica. Santiago, Chile: Editorial Universitaria, 2004.

Heinsch, Robert. The Crime of Aggression after Kampala: Success or burden for the future? En: Goettingen Journal of International Law, 2(2): 713-743, 2010.

Hobbes, Thomas. Leviatán, o de la materia, forma y poder de una república eclesiástica y civil. Buenos Aires, Argentina: Fondo de Cultura Económica, 1992.

HöFfe, Otfried. El proyecto político de la modernidad. Buenos Aires, Argentina: Fondo de Cultura Económica, 2008.

Homero. La Ilíada. Madrid, España: Gredos, 2006.

Hublin, Jean-Jacques y Tillier, Anne-Marie (comp.). Homo Sapiens. En busca de sus orígenes. D.F., México: Fondo de Cultura Económica, 1999.

Insituto de Democracia y Derechos Humanos (IDEHPUCP), PUC del Perú. El crimen de agresión después de Kampala: Soberania de los Estados y lucha contra la impunidad. Lima, IDEHPUCP, 2011

Jocelyn-Holt, Alfredo. Historia General de Chile. Tomo Uno: El retorno de los dioses. Santiago, Chile: Sudamericana, 2004

Jorgensen, Christer. Grandes Batallas. Los combates más trascendentes de la historia. Barcelona, España: Parragon, 2009.

Kant, Immanuel. La paz perpetua. Madrid, España: Tecnos, 1998.

MacIntyre, Alasdair. After Virtue. -3a . ed.- Indiana, Estados Unidos: University of Notre Dame Press, 2007.

Maquiavelo, Nicolás. El Príncipe. Buenos Aires, Argentina: Gradifco, 2004.

McNeILl, William. Keeping together in time. Cambridge (MA), Estados Unidos: Harvard University Press, 1995.

Meilaender, Gilbert. War and Techne, en: The New Atlantis: 45-53, verano 2003.

Mill, John Stuart. On Liberty. CIUDAD, Estados Unidos: The Liberal Arts Press, 1956.

Moreno de Del Cueto, Carmen. La importancia de los Convenios de Ginebra en la evolución del derecho internacional público. En: Fraidenraij, Susana y Méndez, Ricardo (comp.). Elementos de derecho internacional humanitario. D.F., México: UNAM, 2001, pp. 21-28. 
Mouffe, Chantal. El retorno de lo político. Barcelona, España: Paidós, 1999.

Norton, John. Prolegomenon to the jurisprudence of Myers McDougal and Harold Laswell. Virginia Law Review, 54: 662-688, 1968.

O'Connor, Laurie. Humanitarian Intervention and the Crime of Aggression: The precarious position of the "Knights of Humanity”. Tesis (Bachiller en Derecho), Dunedin, Nueva Zelanda, Universidad de Otago, 2010. 74p.

Orend, Brian. Kant's Just War Theory. Journal of the History of Philosophy, 37(2): 323-353, abril 1999.

Pfanner, Toni. La guerra asimétrica desde la perspectiva de la acción y el derecho humanitarios. Revista Internacional de la Cruz Roja, 857: 149-174, marzo 2005.

Military uniforms and the law of war. International Review of the Red Cross, 86(853): 93-124, marzo, 2004.

Salazar, Eduardo. Violencia, Agresión y Guerra. Santiago, Chile: Ediciones Ercilla, 1943.

Scheler, Max. El puesto del hombre en el cosmos. La idea de paz perpetua y el pacifismo. Barcelona, Espańa: Alba Editorial, 2000.

Schmitt, Carl. El concepto de lo "político". En: Aguilar, Orestes. Carl Schmitt: Teólogo de la política. D.F., México: Fondo de Cultura Económica, 2001. pp. 167-223.

Teoría de la Constitución. Madrid, España: Alianza, 2001.

SEARLE, John. La construcción de la realidad social. Barcelona, España: Paidós, 1997.

Sloterdijk, Peter. Rage and time. A psychopolitical investigation. Nueva York, Estados Unidos: Columbia University Press, 2010.

Sмiтн, Thomas. The New Law of War: Legitimizing Hi-Tech and Infrastructural Violence. International Studies Quarterly, 46: 355-374, 2002.

Strauss, Leo. ¿Qué es filosofía política? Madrid, España: Guadarrama, 1970.

. Natural rights and history. Chicago, Estados Unidos: The University of Chicago Press, 1953.

Swinarsky, Christophe. Derecho internacional humanitario como sistema de protección de la persona humana en su relación con el derecho internacional de los derechos humanos. En: Fraidenraij, Susana y MÉndez, Ricardo (comp.). Elementos de derecho internacional humanitario. D.F., México: UNAM, 2001, pp. 39-65.

TAYLOR, Charles. Fuentes del yo: La construcción de la identidad moderna. Barcelona, España: Paidós, 1996.

Tucídides. Historia de la Guerra del Peloponeso. Libro V. Madrid, España: Gredos, 1992.

Tzu, Sun. El arte de la guerra. Buenos Aires, Argentina: Gradifico, 2008.

Virgilio. La Eneida. Barcelona, España: Ediciones Orbis S.A./Editorial Origen S.A., 1982.

Von Clausewitz, Karl. De la Guerra. Buenos Aires, Argentina: Distal, 2006.

Von Wright, Georg. Norma y Acción. Madrid, España: Tecnos, 1979.

Waldron, Jeremy. Dignity, rank and rights (Tanner Lectures). Marzo, 2009.

WALzer, Michael. Guerras Justas e Injustas. Buenos Aires, Argentina: Goyanarte Editor S.A., 1980.

WeIL, Simone. The Iliad, or the poem of force, en: Chicago Review, 18(2): 5-30, 2003.

WerLe, Gerhard. Tratado de Derecho Penal Internacional. Valencia, Tirant Lo Blanch, 2005.

Zalaquett, José. La desobediencia civil en John Rawls y la ética de medidas de excepción y de medidas extremas. Revista Derecho y Humanidades, 12: 121-132, 2006.

Zorrila, Enrique. La Cristiandad Medieval y su Espiritu Guerrero Caballeresco. Santiago, Chile: RIL Editores, 2000. 